\title{
A Mutant of Chlamydomonas reinhardii with Abnormal Cell Division
}

\author{
By J. R. WAR R \\ Department of Biophysics, King's College, London, W.C. $2^{*}$
}

(Accepted for publication 27 December 1967)

\section{SUMMARY}

A mutant of Chlamydomonas reinhardii with abnormal cell division is described. Cultures of the mutant consist of cells with between one and about seven nuclei. The number of pairs of flagella per cell is the same as the number of nuclei, except in large moribund cells which lack flagella. Pyrenoid division lags behind nuclear division in some cells. The expression of the mutation is modified by the age of the culture, $\mathrm{pH}$ of the environment or by the presence of certain other mutations. Genetic analysis is slightly complicated by the presence of multinucleate gametes, but it is shown that cytokinesis deficiency is inherited as a single gene mutation which maps close to the ac 29 locus on linkage group VI.

\section{INTRODUCTION}

Studies on the effect of mutation on cell division may be fruitful since by blocking the processes of division at a particular stage they may help to clarify the sequence of events in the normal division process. Studies on such mutants should also provide considerable information concerning the genetic control of cell division.

Chlamydomonas reinhardii, a unicellular biflagellate alga, is well suited to a study of the effect of mutation on cytokinesis, although the small size of the chromosomes would be a hindrance to studies on mitosis. The ultrastructure of the organism has been studied in detail (Cavalier-Smith, 1967; Ringo, 1967), genetical techniques are well established (Ebersold \& Levine, 1959; Ebersold, Levine, Levine \& Olmsted, 1962) and large-scale cultures for biochemical experiments may be easily grown in simple inorganic media.

Buffaloe (1958) has shown that cytokinesis in Chlamydomonas reinhardii is by furrowing and two or three rounds of division can occur within the original cell wall, which then bursts to liberate four or eight daughter cells. The second cytokinetic furrow occurs at right angles to the first. More recently, Cavalier-Smith (1967) has studied cytokinesis in $C$. reinhardii in the electron microscope. He showed that the chloroplast starts to divide by furrowing before the commencement of cytokinesis proper and that some of the chloroplast disc membranes are actually cut in two by the advancing furrow. Before the chloroplast division is completed, the cytokinetic furrow starts near the basal bodies and develops in association with cytokinetic microtubules. The flagella regress before division and are regenerated after the completion of cytokinesis.

Lewin has briefly described a mutant of Chlamydomonas moewusii apparently

\footnotetext{
* Present address: Department of Biology, University of York, Heslington, York.
} 
having a deficiency in cytokinesis which leads to multinucleate cells (M 470 in Lewin, 1952). However, relatively little is known of the linkage relationships and genetic techniques of $C$. moewusii. A mutant deficient in cytokinesis has now been isolated in $C$. reinhardii and is the subject of the present paper.

\section{METHODS}

Strains. The mutation for cytokinesis deficiency (cyt $\mathrm{I}$ ) was isolated in this laboratory by Miss Anne McVittie in a wild type, mating type plus strain of Chlamydomonas reinhardii which was obtained from the Cambridge Collection of Algae and originally from Professor R. P. Levine's Laboratory at Harvard. Cells were grown for 2 days on solid medium containing $0.5 \mu \mathrm{g} . / \mathrm{ml}$. $N$-methyl- $N$-nitroso- $N$-nitroguanidine (KochLight, Colnbrook, Bucks) and then replated on semi-solid medium at Ioo per dish. The cytokinesis-deficient mutant was selected on the basis of small colony size and subsequent microscopic examination.

The acetate-requiring and paralysed flagella strains, ac 17, ac $29 \mathrm{~A}, p f 2$ and $p f 20$ were kindly provided by Professor R. P. Levine's laboratory and are described in Ebersold et al. (1962). The origin and phenotype of $p f_{19 \mathrm{~B}}$ is described in Randall, Warr, Hopkins \& McVittie (1964) and Warr, McVittie, Randall \& Hopkins (I966).

General techniques. Culture conditions and crossing techniques were as described in Warr et al. (1966).

Estimation of flagella number. Cells from liquid cultures were fixed in osmium tetroxide vapour and the flagella on each cell counted with phase optics. Over 200 cells were examined in each sample. A very small proportion of cells (0-3\%) were sometimes enclosed in palmella envelopes (thus obscuring the flagella) and are not included in the data.

Staining methods. Nuclear staining was usually by Azure A according to Levine \& Folsome (1959) or less frequently by Feulgen according to Bernstein (I964) after fixation in Carnoy's fixative ( $15 \mathrm{~min}$.) or in osmium tetroxide vapour. Nuclei appeared less granular and better preserved and flagella are intact with osmium, but this fixative left more basophilic material in the cytoplasm than Carnoy's. Pyrenoids were stained with $0.3 \%(\mathrm{w} / \mathrm{v})$ iodine in $\mathrm{I} \%(\mathrm{w} / \mathrm{v})$ potassium iodide. Examination and photography of stained material was in bright-field illumination with apochromatic objectives with either a Zeiss photomicroscope using Ilford Pan F film or a Vickers microscope and camera attachment using Kodak $\mathbf{P} 300$ plates.

Electron microscopy. Cells from log. phase liquid cultures were fixed in $1 \%(\mathrm{w} / \mathrm{v})$ osmium tetroxide ( $\mathrm{pH} 7 \cdot 3$ ) or in $3 \%(\mathrm{v} / \mathrm{v}$ ) glutaraldehyde in $0.2 \mathrm{M}$-cacodylate buffer, pH 7.3. Fixed specimens were dehydrated in acetone and embedded in Araldite. Sections were double stained in uranyl acetate and lead citrate and examined in an A.E.I. 6B electron microscope.

\section{RESULTS}

General description of mutant. Cultures of the cytokinesis-deficient mutant (cyt $\mathrm{I})$ have some apparently normal, oval cells (about $7 \times 12 \mu$ ) with one pair of flagella, but other cells are of unusual shape bearing several pairs of flagella. Cells with 4,6 or 8 flagella are common and some cells with Io to 12 flagella are nearly always present (Fig. I). Cells with up to 20 flagella have been seen occasionally. 
The shape of a cell is related to its number of flagella. Quadriflagellate cells are typically V-shaped with a pair of flagella at the end of each arm (PI. I, fig. I). Cells which have 6 or 8 flagella are sometimes $Y$ - or X-shaped respectively, with a pair of flagella on each arm, although a variety of other shapes is also seen (PI. I, fig. 2). Cells with 10 or 12 flagella are typically of grotesque, irregular shapes (PI. I, fig. 3). Cells with very high numbers of flagella are usually roughly oval or spherical and about $20-30 \mu$ in diameter.

There are also a few cells present which have no flagella and appear moribund (P1. I, fig. 4). In unfixed material these cells are frequently observed to burst, permitting the cell contents to slowly ooze into the surrounding medium. Consequently, the medium in which this mutant is growing always contains a considerable amount of cell debris.

Azure A or Feulgen staining reveals that the normal-shaped cells are uninucleate, whereas V-, Y- or X-shaped cells have a nucleus in each of their 2, 3 or 4 arms (i.e. one nucleus is present for each pair of flagella). Up to seven nuclei may be counted in larger cells (P1. I, fig. 5-8). The proportion of cells with a given number of nuclei always closely corresponds with the proportion of cells in unstained samples of the same material with an equal number of pairs of flagella. It seems reasonable to conclude that the number of nuclei in a particular cell equals the number of flagella pairs on that cell. Occasional very large cells certainly have more than seven nuclei but overlapping makes reliable counting difficult.

The nuclear size in multinucleate cells appears similar to that of wild-type cells, although quantitative measurements of nuclear diameter or microspectrophotometric determination of DNA content have not yet been performed. Occasionally large cells appear to have large diffuse nuclei, but this may reflect the moribund nature of such cells.

Uninucleate cells have a single pyrenoid. In V-shaped binucleate cells there are usually two pyrenoids, but in about $15 \%$ of these cells there is a single round pyrenoid at the base of the $\mathrm{V}$ (Pl. I, fig. 9). In larger cells it is sometimes difficult to count numbers of pyrenoids due to overlapping.

The mutant has been examined in the electron microscope by J. M. Hopkins in this laboratory with particular attention being given to the bridge region between two cell parts of binucleate cells. In some cells the chloroplast division is incomplete as well as cytokinetic furrow formation (P1. 2, fig. 10), whereas in other cells it appears that the chloroplast division has been completed with only cytokinetic furrow development blocked in its final stages (PI. 2, Fig. II). Cytokinetic microtubules have not so far been detected in this strain (although flagellar root microtubules have been seen).

It is necessary to consider whether cytokinesis in cyt I multinucleate cells has been halted and will not go to completion or whether it is merely proceeding slowly. An approach to this problem has been made by dissection of some of the largest cells of a cyt I strain on to solid medium using the zygote isolation technique of Ebersold \& Levine (1959). The very large size of the dissected cells suggested eight or more flagella per cell, but in the absence of phase optics it was not possible to count the flagellar number precisely. Nine out of 18 such cells gave rise to colonies containing the characteristic range of $c y t$ I cell types. Thus, approximately $50 \%$ of large multinucleate cells are capable of eventually completing cytokinesis.

Lewin (1952) observed that a multiflagellate mutant of Chlamydomonas moewusii 
also differed from wild type in its level of resistance to sodium citrate. cyt I strains, however, have the same level of citrate resistance as wild-type $C$. reinhardii.

Effect of age of culture on cyt $I$. During the course of preliminary studies with the mutant, it appeared that the number of multiflagellate cells decreased with the age of the culture. To investigate this more fully a liquid culture was sampled from early log. phase well into stationary phase and the distribution of cell types in each sample determined. The results are summarized in Fig. 2, which shows that the mean number of flagella per cell rises during log. phase from about three to nearly four. With the

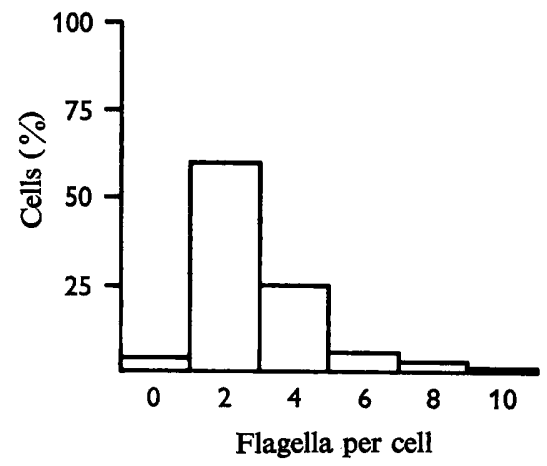

Fig. I

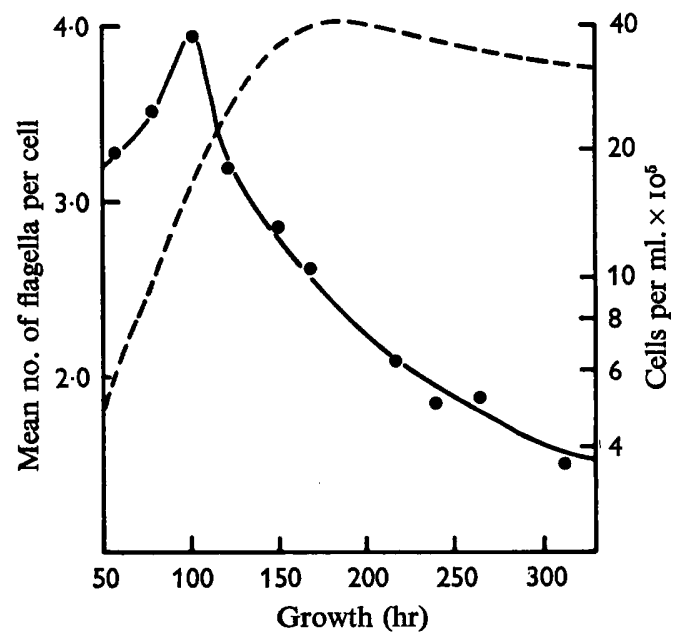

Fig. 2

Fig. I. Proportions of cells with various numbers of flagella in a $\log$ phase culture of $c y t \mathrm{I}$.

Fig. 2. Effect of age of culture on the mean flagella number per cell of cyt I. $-\longrightarrow$, Mean number of flagella per cell. - -, Total number of cells per ml. plotted on a log. scale.

onset of stationary phase, the mean flagella number falls sharply. Figure 3 shows more detailed data from the same experiment. It can be seen that the proportion of biflagellate, uninucleate cells falls to $40 \%$ in log. phase but rises to about $70 \%$ once stationary phase has been attained. Cells with four or more flagella reach a maximum of over $50 \%$ by mid log. phase but decline to about $10 \%$ after a time in stationary phase. Cells without any flagella (i.e. mostly moribund cells) increase steadily during stationary phase.

Effect of pH on cyt $\mathrm{I}$. The effect of $\mathrm{pH}$ on cyt $\mathrm{I}$ was studied by growing a series of cultures buffered with phosphate between $\mathrm{pH} 6$ and $\mathrm{pH}$ 8. As shown in Fig. 4, the mean number of flagella per cell rises from 2.6 to 3.9 over this $\mathrm{pH}$ range. More detailed data from the same experiment is shown in Fig. 5 .

Interaction of cyt $I$ with other mutations. In strains carrying cyt $\mathrm{I}$ together with certain mutations causing paralysis of flagella ( $p f 2, p f$ I9 B or $p f 20$ ) the proportion of multiflagellate cells is consistently lower than in strains carrying $c y t$ I alone. The distribution of cell types in such a double mutant is shown in Fig. 6, which may be compared with the distribution observed in cultures of $c y t$ I alone shown in Fig. I. (These two cultures were examined at a similar stage of growth and are taken from a single experiment). 
Strains carrying paralysed flagella mutations grow at the bottom of the culture vessel and it was considered possible that bottom growth could alter the cell environment in such a way as to affect the expression of $c y t \mathrm{I}$. However, this was discounted by growing cultures under conditions of gentle agitation to prevent settling of cells. Under these conditions the double mutants still had a consistently lower proportion of multiflagellate cells than strains carrying $c y t$ I alone.

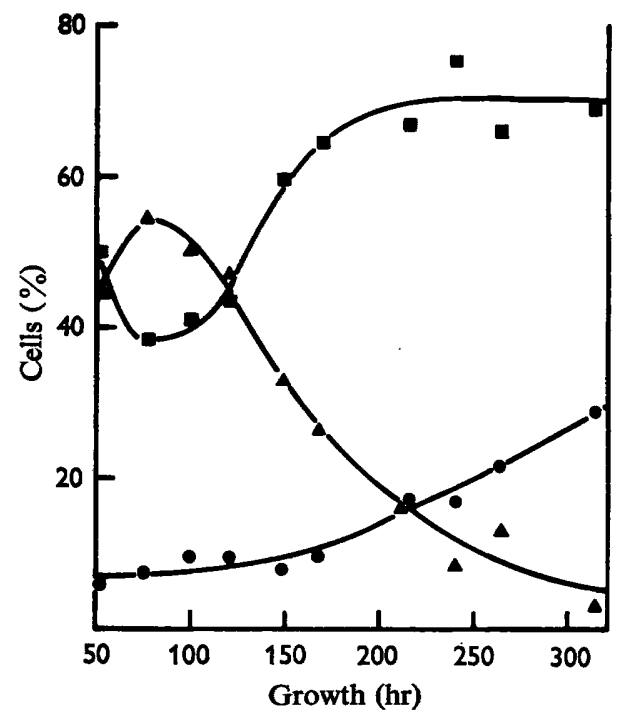

Fig. 3

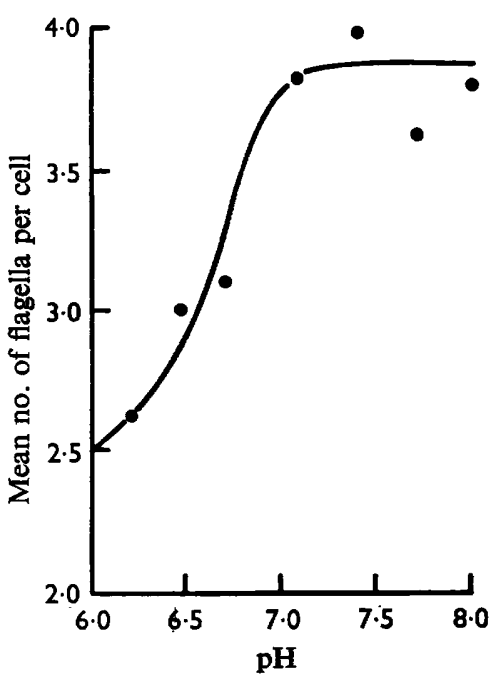

Fig. 4

Fig. 3. Effect of age of culture on the proportions of biflagellate, multiflagellate and aflagellate cells of cyt I. $\longrightarrow$, Cells with two flagella. $\Delta \longrightarrow \Delta$, Cells with four or more flagella. Cells with no flagella (mostly moribund cells).

Fig. 4. Effect of $\mathrm{pH}$ on the mean flagella number per cell in a log phase culture of cyt $\mathrm{r}$. Cells grown in $1.5 \times 10^{-2} \mathrm{M}$-phosphate buffer plus normal nutrient salts except phosphate. $\mathrm{pH}$ of medium measured at time of taking cell samples.

Genetic analysis. Gametes of Chlamydomonas reinhardii differentiate directly from vegetative cells on transfer to nitrogen-free medium (Sager \& Granick, 1954). Consequently, a high proportion of gametes of this mutant are multinucleate, which would seem $a$ priori likely to complicate genetic analysis. It is therefore not unexpected that in the nine crosses so far performed between cyt I strains and wild type the germination of zygotes has been rather low (range 60-97\%, mean $86 \%$ ) and that other anomalies have been observed. On germination each Chlamydomonas zygote normally liberates 4 or 8 spores which each give rise to a progeny clone (Ebersold \& Levine, I959). In cyt I crosses, however, approximately one-third (range $15-47 \%$, mean $32 \%$ ) of the germinating zygotes give rise to abnormal numbers of spores or to progeny clones of pale granular cells which form very small colonies on solid medium. These colonies probably arise from matings involving multinucleate gametes of $c y t$ I which lead to irregular meiosis in some zygotes with consequent formation of zoospores with abnormal chromosome complements.

Allowing for these discrepancies, it may be shown that cyt $\mathrm{I}$ is inherited as a single 
gene difference. In crosses with normal strains, microscopic examination of progeny clones from 23I zygotes having normal germination showed $222(96 \cdot 1 \%)$ with $2: 2$ segregation of cytokinesis deficient to normal types. The nine exceptional zygotes are thought to arise by a process similar to that discussed in the previous paragraph. This hypothesis is supported by the finding that a similar small proportion of zygotes from these crosses show irregular segregation ratios for well-established chromosomal genes.

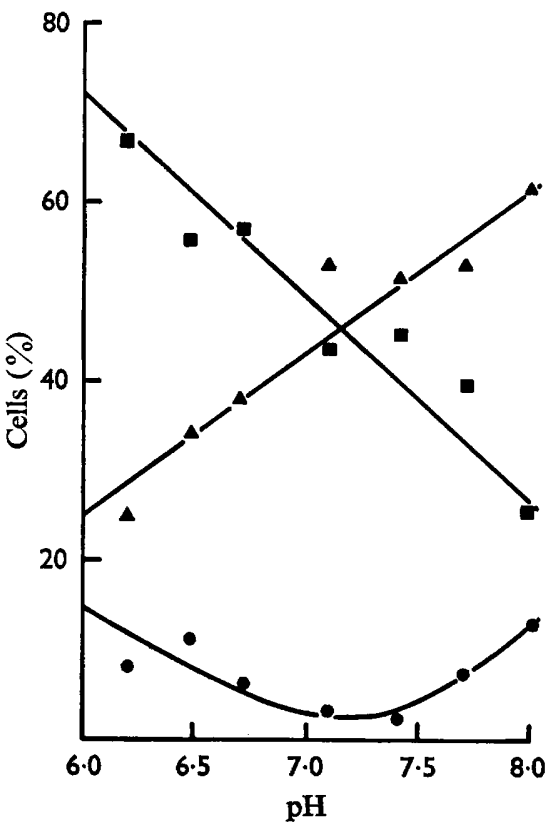

Fig. 5

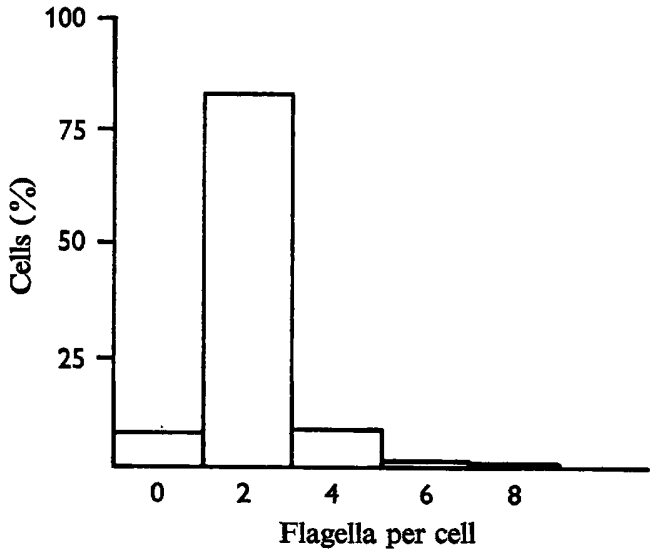

Fig. 6

Fig. 5. Effect of pH on the proportions of flagellate, multiflagellate and aflagellate cells in a $\log$. phase culture of $c y t \mathrm{I}$. $\square$, Cells with two flagella. $\Delta-\boldsymbol{\Delta}$, Cells with four or more flagella. Cells with no flagella (mostly moribund cells).

Fig. 6. Proportions of cells with various numbers of flagella in a log. phase culture of the double mutant pf 2 ; cyt $\mathrm{I}$. This culture was grown under the same conditions as the culture carrying cyt $\mathrm{I}$ alone represented in Fig. I. The double mutant has more biflagellate cells but fewer cells with four or more flagella.

Preliminary mapping experiments indicate free recombination between $c y t \mathrm{I}$ and the $a c \mathrm{I} 7, p f 2, p f$ I9 or $p f 20$ loci but demonstrates close linkage to the $a c 29$ locus, which is on the left arm of linkage group VI, close to the mating-type locus, (Ebersold et al. 1962). In the cross $c y t \mathrm{I}, a c 29 \mathrm{~A}^{+}, m t^{+} \times c y t \mathrm{I}^{+}, a c 29 \mathrm{~A}, m t^{-}$germination was $85 \%$ with $24 \%$ of germinating zygotes giving abnormal progeny types (see above). Classification of I 7 normal tetrads for $c y t$ I and ac $29 \mathrm{~A}$ showed I 7 parental ditype, no non-parental ditype and no tetratype tetrads, indicating close linkage between these two loci (Perkins, 1953). A more detailed analysis of the linkage relationships between cyt $\mathrm{I}$ and markers on linkage group VI is now in progress. 


\section{DISCUSSION}

In order to understand the mode of expression of this mutation we may first consider the timing of organelle duplication in the mutant and the wild type. The most important feature of this in the mutant is that there is good correlation between the number of nuclei and pairs of flagella per cell. Cavalier-Smith (1967) described a fibrous band, devoid of ribosomes, passing between the interphase nucleus and the basal bodies of Chlamydomonas reinhardii which may provide the physical basis for this observation. Buffaloe (1958) has shown that in wild-type $C$. reinhardii, pyrenoid division is always completed before cytokinesis occurs. Consequently, the finding that I $5 \%$ of V-shaped binucleate cells in the mutant have only a single pyrenoid clearly indicates that pyrenoid division tends to be delayed, as does completion of the chloroplast furrow. Thus it may be that division of nuclei and flagella on one hand and chloroplast and pyrenoid on the other are under separate systems of control. In this context it is of interest that the mutation has been shown to be in a chromosomal gene.

It may also be noted that in the stable diploid strains of Chalmydomonas reinhardii recently described by Ebersold (1967) there is apparently a single pyrenoid with each large diploid nucleus, showing that in these strains the number of pyrenoids is related to the number of nuclei and not the number of chromosomes in the cell.

A second approach to the problem of gene action is through an examination of the effects of environmental factors on the expression of the mutation. Since flagellar number can be readily determined in unstained material and is related to nuclear number, it provides an easily obtained quantitative measure of cytokinesis deficiency and hence of gene expression. This criterion has been used to show that $\mathrm{pH}$ alters gene expression and it may now be possible to demonstrate further changes in the presence of specific chemical substances, thus providing clues to the nature of the deficiency in the mutant. Stevens $(1966 a, b)$ has shown that the proportion of multinucleate cells in cultures from hamster ascites tumours is reduced by thymidine triphosphate or a combination of estrone and cancer serum.

It has been shown that the proportion of binucleate cells rises in log. phase cultures of the mutant then falls when stationary phase is attained. The increase in the proportion of uninucleate cells during stationary phase suggests the cytokinesis can eventually catch up with nuclear division in some cells at least. The proportion of binucleate cells in mouse liver increases with age although subsequently there is an increase in polyploid cells (Epstein, 1967). It would be important to investigate by quantitative microspectrophotometry whether polyploid nuclei are formed in stationary phase cultures of the mutant.

Before further genetic analysis is undertaken with this or other similar mutants, it would be preferable to eliminate multinucleate gametes since they inevitably complicate such analysis. Preliminary attempts to remove these larger cells from cultures by filtration or centrifugation have not been successful. More progress may come from investigation of environmental conditions which mitigate the deficiency in cytokinesis and maximize the proportion of uninucleate cells in a culture.

I wish to thank Professor Sir John Randall, F.R.S., for support and advice during this work and Miss Anne McVittie for many valuable suggestions and for making available the original isolate of the mutant. Thanks are also due to Mr J. M. Hopkins 
for taking the electron micrographs, to $\mathrm{Mr}$ T. C. Appleton for advice on photography and especially to Miss Penny Wright for excellent technical assistance.

\section{REFERENCES}

Bernstein, E. (1964). Physiology of an obligate photoautotroph (Chlamydomonas moewusii). 1. Characteristics of synchronously and randomly reproducing cells and a hypothesis to explain their population curves. J. Protozool. II, 56.

BUfFaloe, N. D. (1958). A comparative cytological study of four species of Chlamydomonas. Bull. Torrey bot. Club. 85, 157.

CAvalIER-Smith, T. (1967). Organelle development in Chlamydomonas reinhardii. Ph.D. thesis, University of London.

EBERSOLD, W. T. (1967). Chlamydomonas reinhardii: heterozygous diploid strains. Science, N.Y. 157, 447.

EBersold, W. T. \& LEVINe, R. P. (1959). A genetic analysis of linkage group I of Chlamydomonas reinhardi. $Z$. VererbLehre 90, 74 .

Ebersold, W. T., LeVine, R. P., LeVINe, E. E. \& Olmsted, M. A. (1962). Linkage maps in Chlamydomonas reinhardi. Genetics, Princeton 47, $53 \mathrm{I}$.

EPSTEIN, C. J. (1967). Cell size, nuclear content, and the development of polyploidy in the mammalian liver. Proc. natn. Acad. Sci. U.S.A. 57, 327.

LeVINE, R. P. \& Folsome, C. E. (1959). The nuclear cycle in Chlamydomonas reinhardi. Z. VererbLehre 90, 215 .

LEWIN, R. A. (1952). Ultraviolet induced mutations in Chlamydomonas moewusii Gerloff. J. gen. Microbiol. 6, 233.

Perkins, D. D. (1953). The detection of linkage in tetrad analysis. Genetics, Princeton 38, 187.

Randall, J. T., WARR, J. R., Hopkins, J. M. \& McVirtie, A. (I964). A single gene mutation of Chlamydomonas reinhardii affecting motility: a genetic and electron microscope study. Nature, Lond. 203, 912.

RINGo, D. L. (1967). Flagellar motion and fine structure of the flagellar apparatus in Chlamydomonas. J. cell. Biol. 33, 543 .

SAGER, R. \& GRANICK, S. (1954). Nutritional control of sexuality in Chlamydomonas reinhardi. J. gen. Physiol. 37, 729.

STEVENS, D. F. (1966a). Mechanisms influencing cytokinesis in hamster ascites multinucleated cells. The effect of some citrate cycle inhibitors and nucleotides. Expl Cell Res. 4I, 492.

Stevens, D. F. (1966 b). Actinomycin D or puromycin inhibition of cancer serum and estrone or thymidine- $5^{\prime}$-triphosphate induced cytokinesis in hamster multinucleated tumour cells. Expl Cell Res. 44, 498.

WarR, J. R., McVittie, A., Randall, J. T. \& Hopkins, J. M. (1966). Genetic control of flagellar structure in Chlamydomonas reinhardii. Genet. Res. 7, 335.

\section{EXPLANATION OF PLATES}

\section{Plate I}

Photograph of cells from log. phase culture of cyt $\mathrm{I}$.

Figs. I-4. Phase contrast, $\times$ III5.

Fig. I. V-shaped cell with 4 flagella adjacent to a normal oval cell with two flagella. The light regions near the base of the cells are pyrenoids.

Fig. 2. Cell with eight flagella. Note the arrangement of flagella in pairs.

Fig. 3. Large cell with I I visible flagella. At least I other flagellum is out of focus or behind the cell. Fig. 4. Very large, moribund cell lacking flagella close to a normal biflagellate cell.

Figs. 5-8. Azure A stained. Bright field, $\times$ I 125.

Fig. 5. Group of V-shaped binucleate cells and oval uninucleate cells. Darkly staining regions are nuclei, light circles are pyrenoids.

Fig. 6. Y-shaped cells with three nuclei, adjacent to uninucleate cells. 
Journal of General Microbiology, Vol. 52, No. 2

Plate I
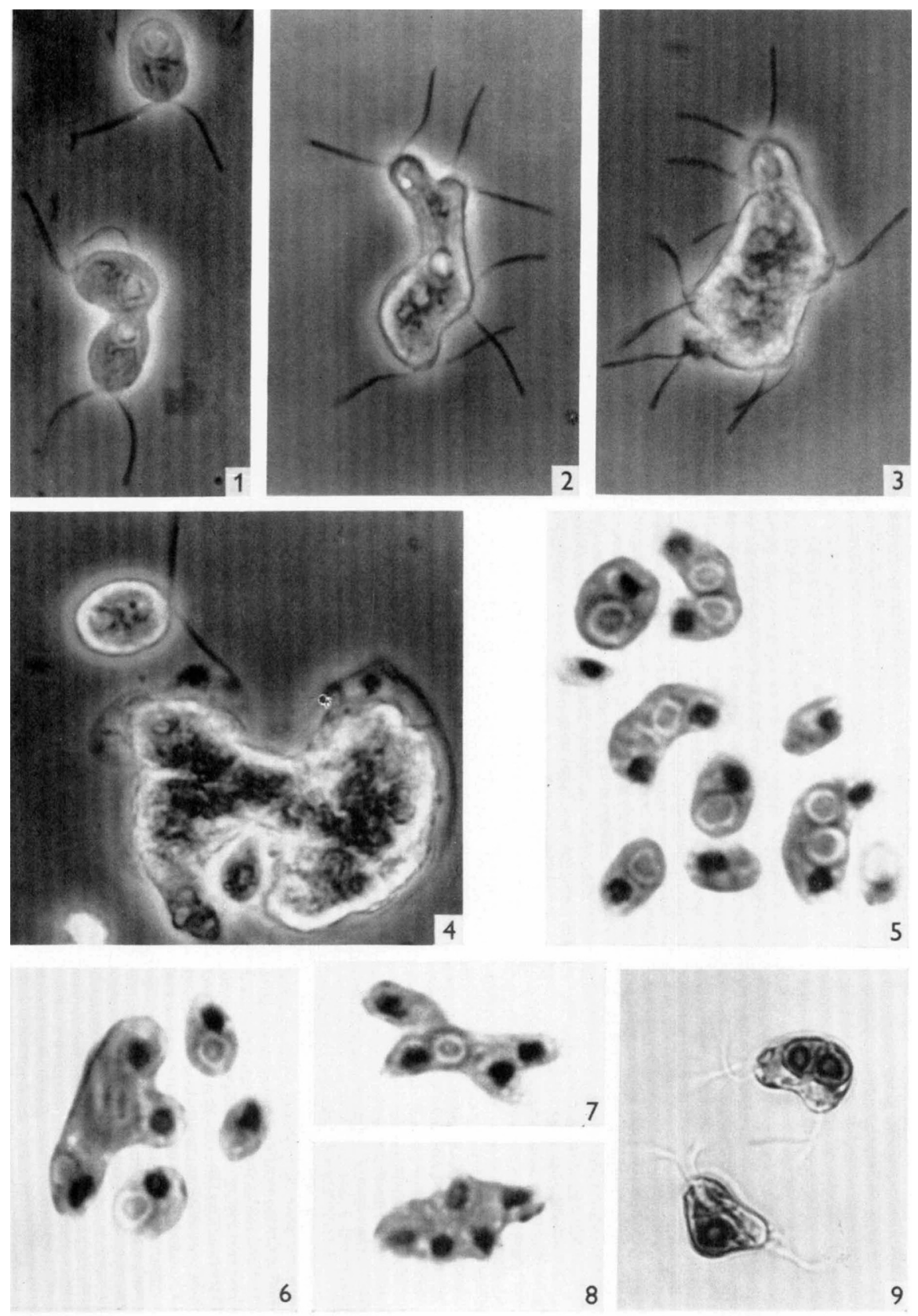

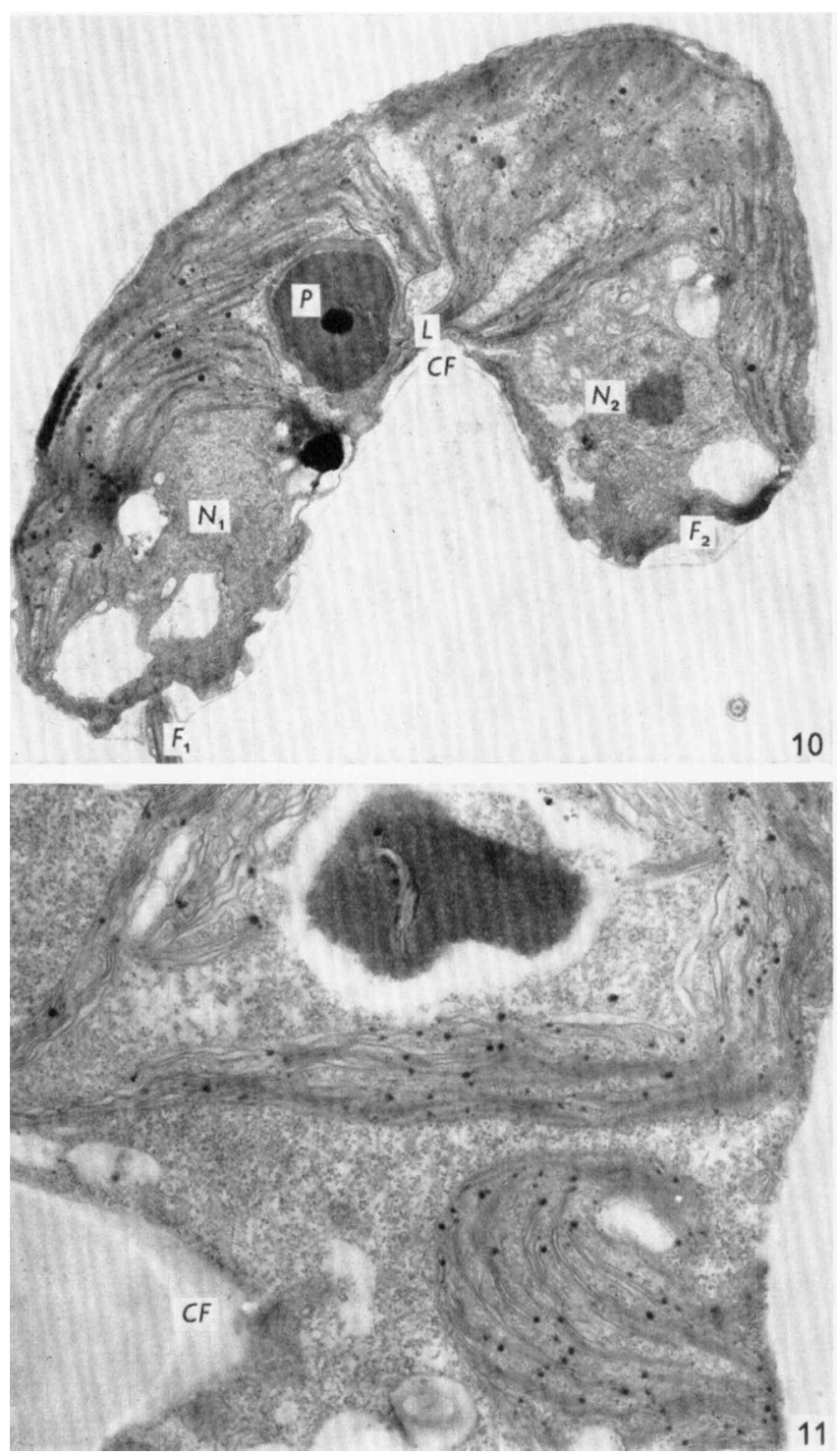
Fig. 7. X-shaped cell with four nuclei.

Fig. 8. Cell with five nuclei. Only one nucleus is sharply in focus.

Fig. 9. V-shaped cells with four flagella (more clearly visible with phase optics) stained with iodine to show the pyrenoids. One quadriflagellate cell has two pyrenoids, the other has only one. Bright field, $\times 560$.

\section{Plate 2}

Fig. IO. Electron micrograph of a $\mathrm{V}$-shaped cell of $c y t \mathrm{I}$. The section passes through the two nuclei $\left(N_{1}, N_{2}\right)$, parts of the flagellar apparatus $\left(F_{1}, F_{2}\right)$ and a single pyrenoid $(P)$. Cytokinetic furrow formation $(C F)$ and chloroplast division are incomplete; note the continuous chloroplast lamellae $(L)$ running between the two cell portions. Osmium tetroxide fixation $\times 9400$.

Fig. II. Higher magnification electron micrograph of the bridge region of a different $V$-shaped cell showing complete division of the chloroplast. The cytokinetic furrow $(C F)$ is still incomplete. Osmium tetroxide fixation, $\times 18,750$. 